\title{
“OBSERVAMOS MAL, NO LLEGAMOS AL FONDO DE LAS COSAS".
}

Comentario crítico sobre Sandra Gasparini. Espectros de la ciencia. Fantasía cientifica de la Argentina del siglo XIX. Buenos Aires: Santiago Arcos, 2012. 339 pp.

Luciana Martinez. UNR CONICET

Hace poco más de un año mientras escribía una reseña de ese libro iluminador de Ezequiel De Rosso sobre el policial en el siglo XX tuve la oportunidad de reafirmar una hipótesis que tenía desde hacía años (a propósito de un autoanálisis de mi propia neurosis): en los trabajos de todos aquellos que escribimos - vuelta más, vuelta menos- sobre géneros, se cifra ineludiblemente un mito de origen; y de ahí (deducía entonces salvaje e intrusivamente) el halo melancólico que recorre las páginas del libro de De Rosso cada vez que éste aborda el problema de la desintegración genérica.

Terribles peripecias de mudanza, avatares de la inestabilidad laboral (y a veces también emocional), me impidieron sentarme antes a reseñar este esperado libro de Sandra Gasparini, cuyo trabajo sigo desde hace años. Espectros de la ciencia venía como mirándome de reojo desde el estante, hasta que hace poco por suerte terminó imponiéndoseme su abordaje. En el comienzo encontré (¡oh, sorpresa!): el mito de origen de Sandra ligado a su pasión por las representaciones literarias de la ciencia. Más allá de reconocer el remanido gesto ensayístico, al que también 
suelo adscribir quizás con demasiada frecuencia, sentí como si me mirara en un espejo: la génesis cifrada en el recelo hacia las certezas de los sentidos y el estatuto irreal de los sueños, todo lo cual se traduce en una pregunta ontológica de lo que entendemos por realidad. Ya somos casi un club, lástima que haya algunos occisos y un océano de anacronismo ( $\mathrm{y}$ de talento) de por medio: Philip Dick, Mario Levrero, Aldous Huxley (podríamos seguir la serie amorosa, claro está) y, pudor aparte, Sandra Gasparini y yo. Siempre se lee, sin duda, desde esa primera inquietud que nos constituye, y que nos ha dejado envueltos en su telaraña.

Cuando me adentré en la lectura del texto de Gasparini, hacía no mucho había tenido la inestimable oportunidad de moverme de ciertos temas de mi preferencia (este libro no era el caso) para recorrer senderos que no tenían en absoluto que ver; en aquella instancia pude releer los clásicos El género gauchesco (1988) y El cuerpo del delito (1999), de Josefina Ludmer, y el que por aquél entonces todavía tenía su tinta fresca, El país de la guerra (2014) de Martín Kohan -muy bueno por cierto. En ese contexto, un poco inesperadamente, el texto de Gasparini aportó una pieza al mapa que tenía de la literatura del XIX argentino, al que recién en ese momento pude notar le venía faltando una arista importante.

La indiscernible relación entre el proyecto de la elite política de la generación del ochenta en torno a la conformación de la Nación y la producción literaria no podía no tocar aquel punto en el que se apoya cualquier concepción ulterior (pero también siempre histórica) de lo real: la ciencia. Si la literatura en el siglo XIX formó parte de un proyecto de construcción de nación que definió un nosotros y un otro, y asimismo permitió delimitar un orden y funcionamiento de sus instituciones, es perfectamente consecuente que aparezcan en su seno ficcional (aunque seguramente de forma no concertada o lateral dentro 
del proyecto) los problemas de la epistemología, dimensión sobre la que en definitiva descansa toda concepción de mundo.

Con sus bemoles, contradicciones y debates, la literatura en el siglo XIX fue también arena de lucha entre paradigmas (incluso ella, en efecto, está atravesada al igual que toda institución por dinámicas internas de poder). La literatura: una "coartada" para evaluar hipótesis descartadas o no legitimadas por la ciencia oficial (o paradigma dominante en el campo epistemológico, en términos que le serían caros a Kuhn); eso afirma Sandra Gasparini en Espectros de la ciencia. Fantasía cientifica de la Argentina del siglo XIX, texto en que construye una genealogía de esta forma literaria que tendrá una prolífica continuidad en narrativas centrales del siglo XX: Leopoldo Lugones, Horacio Quiroga y, muy posteriormente, ya en la matriz de la ciencia ficción, Marcelo Cohen. En este último sentido, hay que apreciar que la genealogía de Gasparini mira con acierto hacia el futuro, deja abierta la posibilidad a pensar una lógica persistencia de cierta sensibilidad de la fantasía científica en un género que ha sido poco contemplado por la crítica argentina: la ciencia ficción.

Ahora bien, volviendo al eje del siglo XIX, no es casual que Gasparini ubique allí la génesis de la fantasía científica. Claro está que la literatura, en tanto instrumento central del proyecto político, no podría haber estado al margen del debate en torno a la difundida concepción del progreso indefinido a través de la ciencia. En el marco de creciente alfabetización e incentivo a la formación ciudadana, la función didáctica de la literatura necesariamente apuntó hacia la creación de un nuevo público lector que estuviera familiarizado con los problemas del campo científico. Más precisamente, fue la literatura del escritornaturalista Eduardo Ladislao Holmberg, argumenta Gasparini, la que delimitó una cartografía de los nuevos sujetos históricos de la ciencia a partir de la construcción de sujetos ficcionales: 
el viajero científico, el aprendiz, el rival académico. Como era de esperarse, todo este universo tomaría forma no sin poner en primer plano sus propios contrastes.

Hay que mirar hacia un texto como Dos partidos en lucha, primer exponente de la fantasía científica argentina, para apreciar cómo Holmberg pone en el paño la discusión en relación con dos concepciones de ciencia, sin duda aún disputándose una interpretación de lo real: la constructivista (basada en un andamiaje teórico de impronta idealista, opino) y la objetivista (de claro corte empírico-positivista). Todo esto sucede en el marco de una polémica por aquel entonces en extremo vigente: es el propio protagonista quien cuestiona expresamente el corazón de la currícula de las instituciones académicas que no incluía los nuevos postulados del evolucionismo darwiniano.

Los nuevos paradigmas que despuntaban en el campo epistemológico fueron eje de esta primera fantasía científica, la cual se construyó, en principio, sobre el modelo literario francés de Jules Verne. No obstante, la introducción del novum científico sobre el que se erige la solidez del verosímil genérico (aspecto que será luego central en la ciencia ficción) se ve de alguna manera desestabilizado por paradigmas alternos de gran circulación en la Argentina finisecular, los cuales no dejan de construir también una coherencia propia. Porque, conviene estar atentos: la serie literaria tiene sus propias inflexiones en lo que respecta a problemas del conocimiento. Lejos de estar la ficción sujeta exclusivamente a fenómenos de recepción de las cuestiones científicas, la literatura ha tenido en su haber importantes reflexiones epistemológicas. El saber de la locura (concebida como estado privilegiado para percibir más allá de lo empírico) y el de la experiencia onírica son modulaciones de una epistemología romántica que sin duda ha tenido una importante continuidad hasta nuestros días. Por eso, si bien la 
investidura positivista de Verne es insoslayable a la hora de pensar la fantasía científica argentina, también lo es una figura como la de Camille Flammarion.

El viaje astral del señor Nic Nac a Marte o la imposibilidad de explicar desde la ciencia la presencia fantasmal de Nelly en el cuento cuyo título es homónimo son casos que lejos de imponerse en las ficciones de Holmberg con la economía del género fantástico proponen una conformación siempre coherente que no obstante pone en cuestión el universo positivista, sus alcances a la hora de dar cuenta de lo real. "Observamos mal, no llegamos al fondo de las cosas", esta frase de Flammarion que Gasparini rescata -hay que decirlo: con suma perspicacia- no hace más que dejar en evidencia que en la fantasía científica argentina se desata esa vieja disputa (objeto de cuidados trabajos previos de la autora) entre concepciones de mundo, que sigue jugándose en la arena siempre renovada de la ficción: la dicotomía materialismoespiritualismo. Este debate renueva asimismo la histórica discusión entre empirismo e idealismo en el que un siglo atrás ya se había sumido el romanticismo anglo-alemán. De más está decir, no sorprende la comparación, si se tiene en cuenta, como apunta Gasparini, la temprana recepción de escritores como Poe y Hoffman en el Río de la Plata.

Delimitando una rara intersección entre rechazo y fascinación por los principios que emergen con la física newtoniana, la literatura ha cuestionado desde entonces el concepto de materia propuesto por la física clásica; argumentando precisamente, de las más variadas formas, el carácter incierto de los sentidos, de los que en definitiva depende toda evidencia empírica (en la vereda de enfrente del empirismo, Kant ya habría marcado la cancha: lo que entendemos por mundo objetivo no es más que una síntesis espacio-temporal que el sujeto realiza gracias a facultades 
innatas; especie de recorte de eso que podemos intuir pero que será siempre incognoscible: la “cosa en sî").

Son precisamente las limitaciones que se le atribuyen al empirismo las que abren la puerta a las críticas hacia el positivismo, que en las ficciones (según su dinámica hiperbólica y siempre lúdica) viene de la mano de una apertura equivalente hacia la exploración de los fenómenos psíquicoparanormales para los que la ciencia clásica no tendría respuesta. No obstante, ampliar las miras significa para la literatura que el científico conforme un binomio con el loco y que la experiencia de saber advenga durante el trance del arrobo; es decir: que el conocimiento entre por la puerta trasera. Porque si la filosofía y la ciencia han resignado lo inasible ("la cosa en sí"), la literatura no sólo está lejos de hacerlo sino que se ha declarado, por sus propios medios, soberana de su dominio.

En este contexto, no es sólo Holmberg para Gasparini quien propone en sus ficciones un debate entre paradigmas sino, incluso previamente, Juana Manuela Gorriti. En "Quien escucha su mal oye", Gorriti subvierte con un doble gesto los modos instituidos de abordaje epistemológico: propone a una mujer como figura privilegiada de acceso al conocimiento (quebrando así la hegemonía masculina), el cual adviene como verdad en una instancia que lejos de adaptarse a los cánones científicos se caracteriza por el trance hipnótico. Gorriti construye en este texto una figura femenina en sintonía con el modelo de la Ligeia de Poe (al igual que lo hace Holmberg en "Nelly" y Rubén Darío en "Verónica"), mujer dotada de una sensibilidad hiperestésica que le posibilita un acercamiento a otras realidades a partir del trance, la comunicación telepática, el tránsito por los limbos del moribundo. Hay que percibir el acento puesto en lo paranormal, señala luego Lugones a propósito de este problema, en un comentario sobre "Nelly" 
que el espíritu archivista de Gasparini rescata con astucia. No es casual la apreciación: el universo paranormal tendrá una especial importancia no sólo en Las fuerzas extrañas (1906), sino en otros autores de la serie literaria. Habría que pensar además qué sucede ya durante la segunda mitad del siglo XX con figuras como la de Angélica Gorodischer y Marcelo Cohen, desliza finalmente Gasparini.

Cierta sensibilidad decadente finisecular, propone Gasparini retomando con acierto el trabajo de Carlos Abraham, acompaña y problematiza los postulados de impronta positivista que convergen en el interior de la fantasía científica argentina. Hay sin duda una aspiración de tinte romántico decadente hacia aquello inasible que trascendería el concepto de materia clásica, anhelo que convive en las ficciones con el pragmatismo empirista de la ciencia positivista. Porque aunque la fantasía científica argentina operó bajo los imperativos que en el siglo XIX marcaron la literatura (uso político del discurso literario en la redefinición de las instituciones y nuevas figuras científico-académicas), en la serie literaria operaron sus propias inquietudes epistemológicas ligadas a paradigmas alternos. Se trata de paradigmas epistemológicos en pugna por una definición de lo real. Hay que ver esta disputa jugándose en el seno ficcional.

"Cuando era muy pequeña, al despertar de un bello sueño, tan bello por apartarse del verosímil realista, se me ocurrió que ése era el mundo que verdaderamente tenía relevancia y espesor y que el conocido como "real" era solo un sueño", dice Gasparini, cual poseída por Calderón, en la introducción de Espectros de la ciencia. Interesante comienzo, si advertimos que el concepto de ciencia ha estado marcado históricamente para nosotros (al menos desde la modernidad) por la objetividad, la racionalidad y, por qué no, la actividad mental propia de la vigilia productiva. Para la fantasía científica, llegar 
al fondo de las cosas, "observar mejor", parece implicar (además) poner en juego otras facultades. 